from computed tomography: results from a German cohort study. Radiat Environ Biophys 54: 1-12.

Meulepas JM, Ronckers CM, Smets AM, Nievelstein RA, Jahnen A, Lee C, Kieft M, Lameris JS, van Herk M, Greuter MJ, Jeukens CR, van Straten M, Visser O, van Leeuwen FE, Hauptmann M (2014) Leukemia and brain tumors among children after radiation exposure from CT scans: design and methodological opportunities of the Dutch Pediatric CT Study. Eur J Epidemiol 29(4): 293-301.

Muirhead RC (2015) Letter to the editor: ct scans and cancer risk - confounding or effect modification? Br J Cancer doi:10.1038/bjc.2015.106.

Walsh L, Shore R, Auvinen A, Jung T, Wakeford R (2014) Risks from CT scanswhat do recent studies tell us? J Radiol Prot 34(1): E1-E5.

*Correspondence: Dr M-O Bernier; marie-odile.bernier@irsn.fr (c) 2015 Cancer Research UK. All rights reserved 0007-0920/15

\title{
Hepatitis B virus infection and gastric cancer risk: pitfalls in the potential association
}

\section{X-Z Chen ${ }^{1,2}, \mathrm{R} \mathrm{Wang}^{3,4}$ and J-K Hu${ }^{*, 1,2}$}

${ }^{1}$ Department of Gastrointestinal Surgery, West China Hospital, Sichuan University, Chengdu, China; ${ }^{2}$ Laboratory of Gastric Cancer, State Key Laboratory of Biotherapy, West China Hospital, Sichuan University, Chengdu, China and ${ }^{3}$ Department of Gastroenterology, West China Hospital, Sichuan University, Chengdu, China

Sir,

We read with great interests the retrospective case-control study by Wei et al (2015). As the authors Wei et al introduced that epidemiological study is the first one, which found a potential association between hepatitis B virus (HBV) serology and gastric cancer risk. This main finding is indeed surprising to readers. On the basis of the literature from Chinese CNKI journal database, the prevalence of HBV DNA in gastric cancer tissues is only $0-3 \%$ by PCR test. Therefore, to evidence the causality between HBV infection and gastric cancer risk, a qualified study with adequate statistical power requires a dramatically larger scale of sample size than that of the study by Wei et al (2015). In particular, direct detection of HBV DNA in gastric cancer cells by in situ hybridisation is the most convincing evidence to confirm that association.

As known, WHO has defined Helicobacter pylori as a class I human carcinogen for gastric cancer development (Fock et al, 2013). Besides, Epstein-Barr virus infection is also found to be associated with around 10\% of gastric cancer (Murphy et al, 2009). However, in the study by Wei et al (2015), these two critical confounders were not considered in the logistic regression models. The investigated population in the study by Wei et al (2015) is also collected from an endemic region (Guangzhou Province) of both Helicobacter pylori and Epstein-Barr virus infections in mainland China (Wang and Chen, 2014). Therefore, the results are unable to rule out the confounding effects from these two kinds of infections.

Probably, the association between HBV infection and gastric cancer risk might be biased by chance, imbalance of prevalence of $H$. pylori and/ or Epstein-Barr virus infection in stomach, or potentially indirect linkage between $\mathrm{HBV}$ and those two pathogens. Without the adjustment for those two co-infections, the results may have a risk of misleading readers. Thus, we would like to underline these pitfalls behind interpreting the results to readers and practitioners.

Critically, the epidemiological study Wei et al provides some information about the potential association between HBV infection and gastric cancer risk, but the obvious defect in covariate modelling makes the results still far from public health policy and clinical practice. Despite of that, the interesting findings also suggest further investigations with large scale and well-adjusted model to rule out potential biases.

\section{CONFLICT OF INTEREST}

The authors declare no conflict of interest.

\section{REFERENCES}

Fock KM, Graham DY, Malfertheiner P (2013) Helicobacter pylori research: historical insights and future directions. Nat Rev Gastroenterol Hepatol 10(8): 495-500.

Murphy G, Pfeiffer R, Camargo MC, Rabkin CS (2009) Meta-analysis shows that prevalence of Epstein-Barr virus-positive gastric cancer differs based on sex and anatomic location. Gastroenterology 137(3): 824-833.

Wang R, Chen XZ (2014) High mortality from hepatic, gastric and esophageal cancers in mainland China: 40 years of experience and development. Clin Res Hepatol Gastroenterol 38(6): 751-756.

Wei XL, Qiu MZ, Jin Y, Huang YX, Wang RY, Chen WW, Wang DS, Wang F, Luo HY, Zhang DS, Wang FH, Li YH, Xu RH (2015) Hepatitis B virus infection is associated with gastric cancer in China: an endemic area of both diseases. $\mathrm{Br} J$ Cancer 112(Suppl): 1283-1290.

*Correspondence: Dr J-K Hu; E-mail: hujkwch@126.com

${ }^{4}$ This author co-first senior author.

Published online 12 May 2015

(c) 2015 Cancer Research UK. All rights reserved 0007 - 0920/15

http://creativecommons.org/licenses/by-nc-sa/3.0/ 